Supporting Information

\title{
Modulation of surface energy transfer cascade for reversible photoluminescence $\mathrm{pH}$ sensing
}

Lei Lei, Han Xia, Chang-Keun Lim, Shiqing Xu, ${ }^{*}$ Ke Wang, Yaping Du,

and Paras N. Prasad*

Table S1. Calculation processes for the $\mathrm{X}_{\text {eq }}$ values of different surface ligands.

\begin{tabular}{|c|c|c|c|c|c|c|c|}
\hline Element & $\mathrm{H}$ & C & $\mathrm{O}$ & $-\mathrm{OH}$ & $-\mathrm{COOH}$ & $-\mathrm{COO}^{-}$ & $-\mathrm{CH}_{2}$ \\
\hline$X_{e q}$ & 2.2 & 2.55 & 3.44 & 2.63 & 2.8 & 2.40 & 2.3 \\
\hline & & & $X_{\mathrm{CA}^{-}}=$ & $\frac{2}{63}+2\left(\frac{2}{2}\right.$ & $\frac{20-1}{+\frac{2}{2.05}+2\left(\frac{2}{2}\right.}$ & $\left.\frac{3}{3}\right)+\frac{1}{2.55}=$ & $\begin{array}{l}-=2.50 \\
\overline{5}\end{array}$ \\
\hline & & & $X_{\mathrm{CA}^{2-}}$ & $\frac{2}{63}+\frac{4}{2.8}$ & $\frac{19-2}{\left(\frac{2}{2.05}\right)+2(.}$ & $\left.\frac{3}{2.3}\right)+\frac{1}{2.55}=$ & \\
\hline & & & $X_{\mathrm{CA}^{3-}}$ & $\frac{2}{63}+3\left(\frac{1}{2}\right.$ & $\left.\frac{18-3}{5}\right)+2\left(\frac{3}{2.3}\right)$ & $\frac{1}{\frac{1}{2.55}}=2.2$ & \\
\hline
\end{tabular}

Figure S1-S19

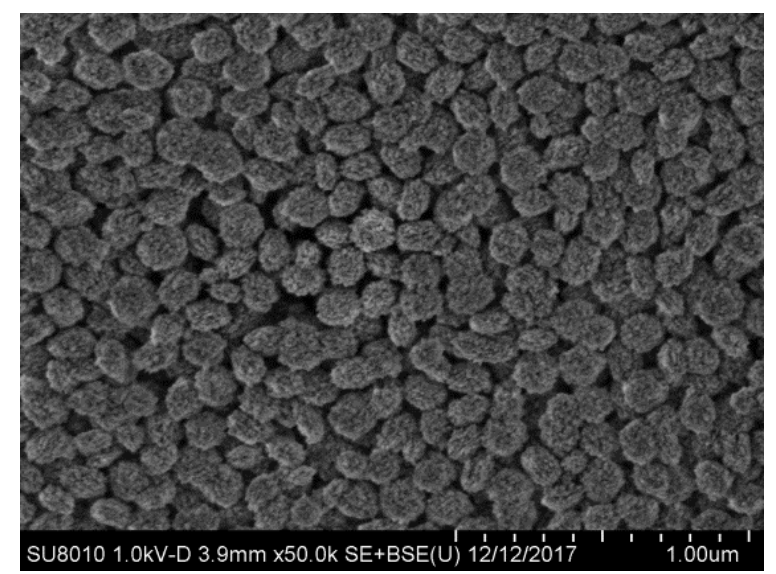

Figure S1. SEM image of 20Ce/6Tb: $\mathrm{NaGdF}_{4} \mathrm{NCs}$. 

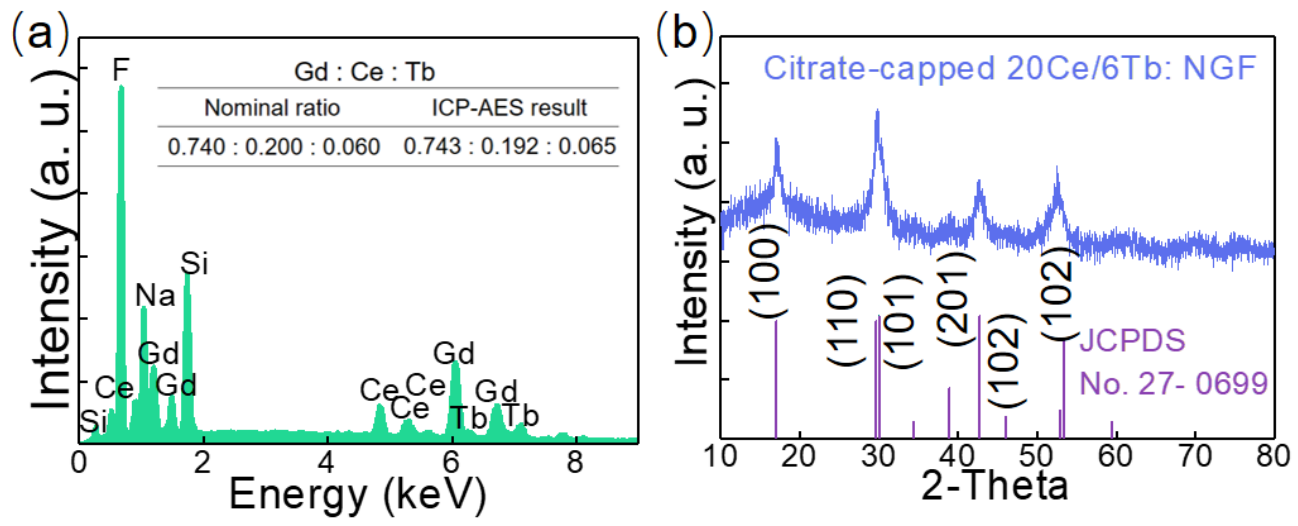

Figure S2. (a) EDS spectra and (b) XRD pattern of $20 \mathrm{Ce} / 6 \mathrm{~Tb}$ : $\mathrm{NaGdF}_{4} \mathrm{NCs}$. Inset in

(a) is the corresponding ICP-AES result.

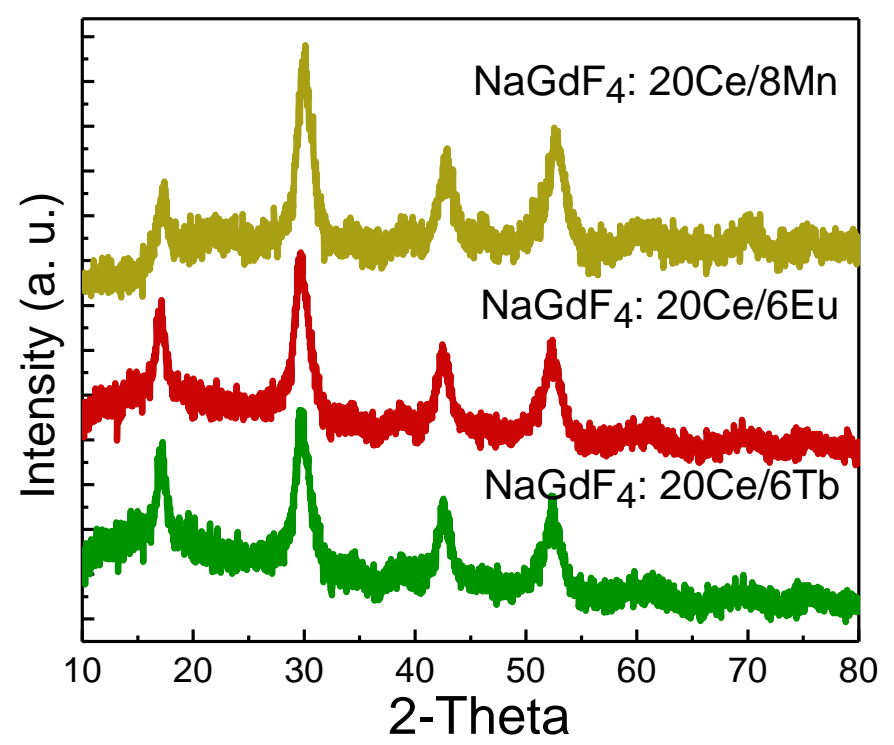

Figure S3. XRD patterns of the Tb-NCs, Eu-NCs, and Mn-NCs. 

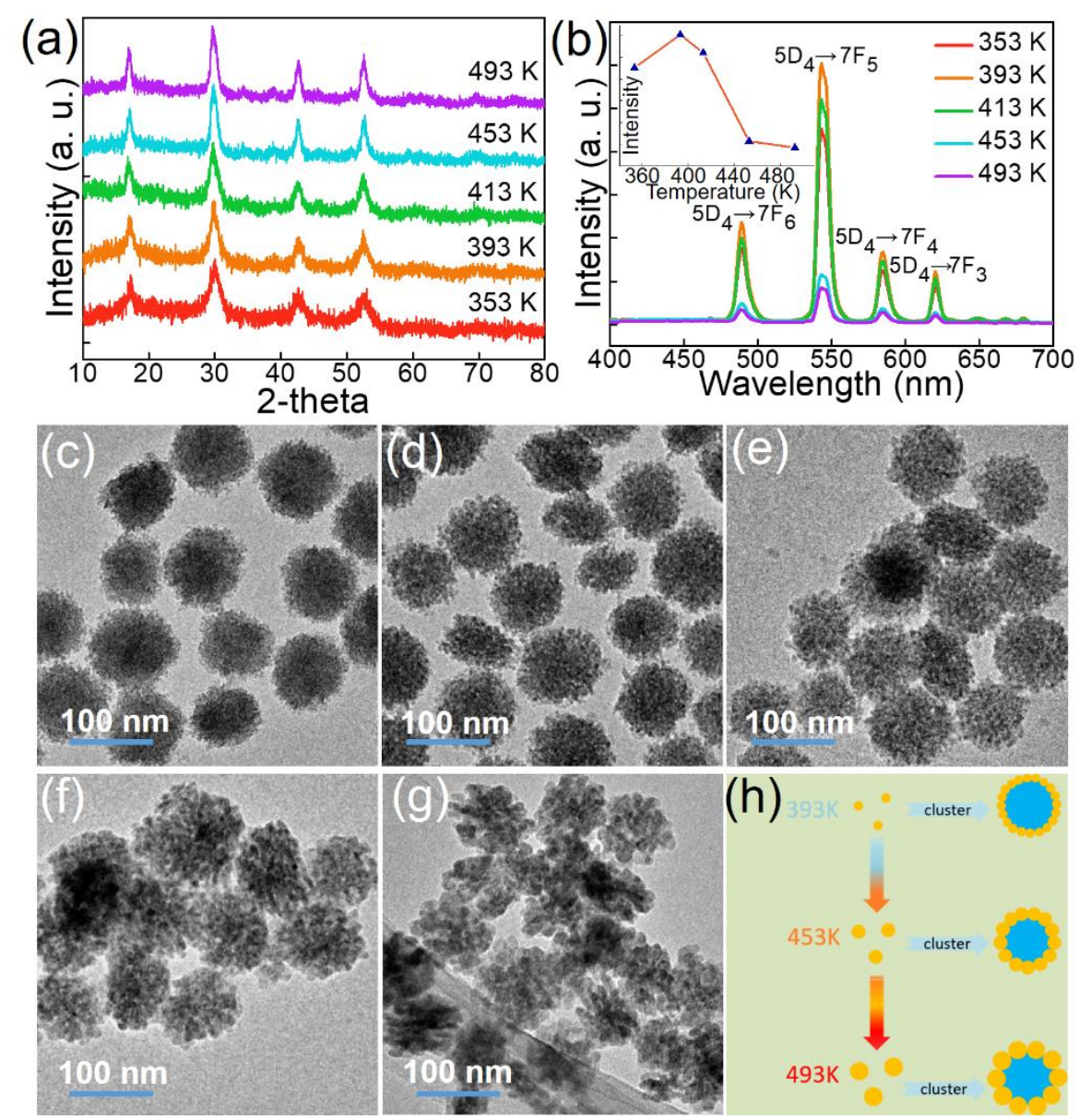

Figure S4. (a) XRD patterns and (b) PL spectra of $20 \mathrm{Ce} / 6 \mathrm{~Tb}$ : $\mathrm{NaGdF}_{4} \mathrm{NCs}$ prepared with different reaction temperature. TEM images of $20 \mathrm{Ce} / 6 \mathrm{~Tb}: \mathrm{NaGdF}_{4} \mathrm{NCs}$ prepared at (c) $353 \mathrm{~K}$, (d) $393 \mathrm{~K}$, (e) $413 \mathrm{~K}$, (f) $453 \mathrm{~K}$ and (g) $493 \mathrm{~K}$, respectively. (h) Schematic illustration for the construction of a big NC from several small single NCs.

XRD diffraction peaks of $20 \mathrm{Ce} / 6 \mathrm{~Tb}$ : $\mathrm{NaGdF}_{4} \mathrm{NCs}$ tended to sharpen with increasing temperature which indicated an increase in their mean crystalline grain size (Figure S4a), and TEM images revealed the increased size was mainly related to the constituent single nanocrystal (Figure S4c-h). 


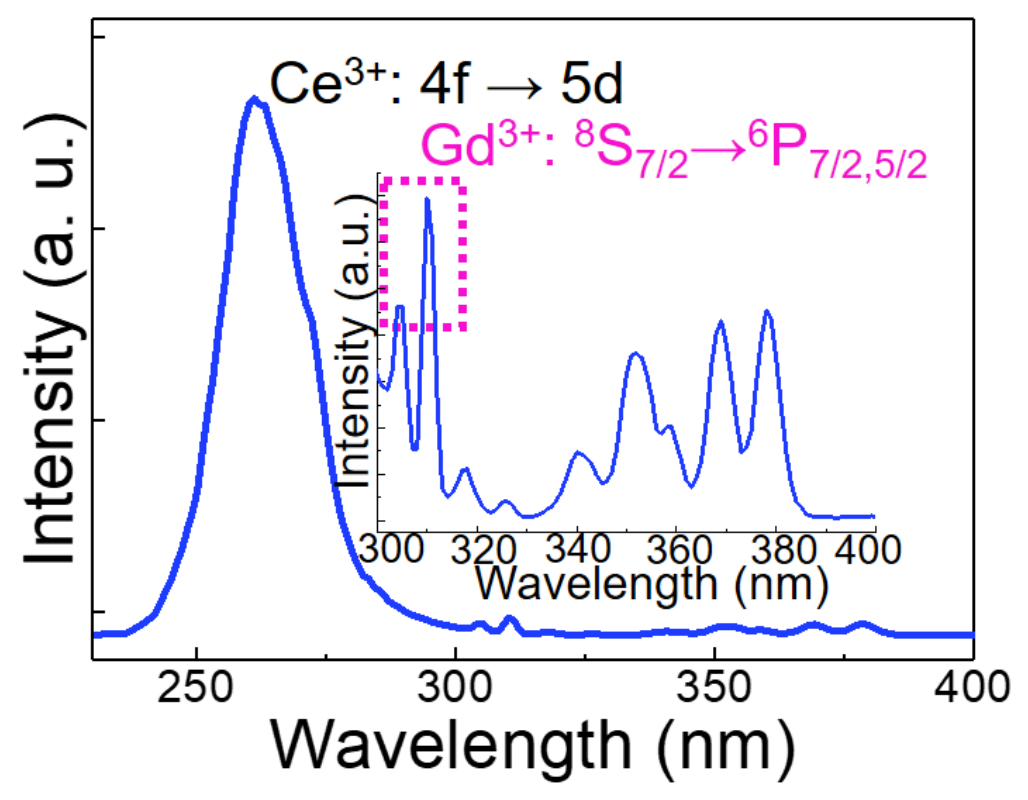

Figure S5. PL excitation spectrum of $20 \mathrm{Ce} / 6 \mathrm{~Tb}$ : $\mathrm{NaGdF}_{4} \mathrm{NCs}$ with monitoring the emission of $\mathrm{Tb}^{3+}$ ions at $548 \mathrm{~nm}$. Inset shows zoom-in spectrum from 300 to $400 \mathrm{~nm}$.

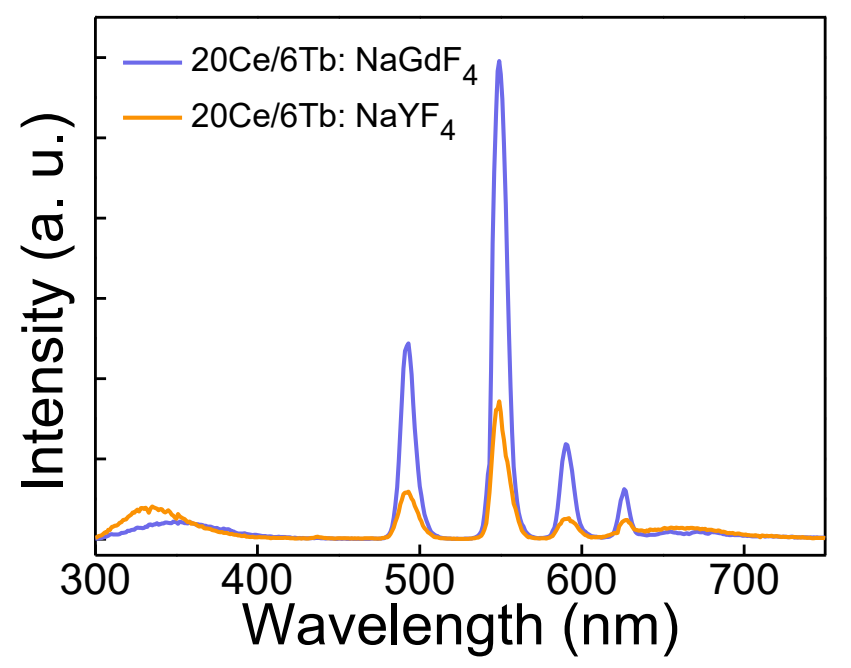

Figure S6. PL spectra of $20 \mathrm{Ce} / 6 \mathrm{~Tb}$ : $\mathrm{NaGdF}_{4}$ and $20 \mathrm{Ce} / 6 \mathrm{~Tb}: \mathrm{NaYF}_{4} \mathrm{NCs}$ prepared under the same reaction temperature and time. 


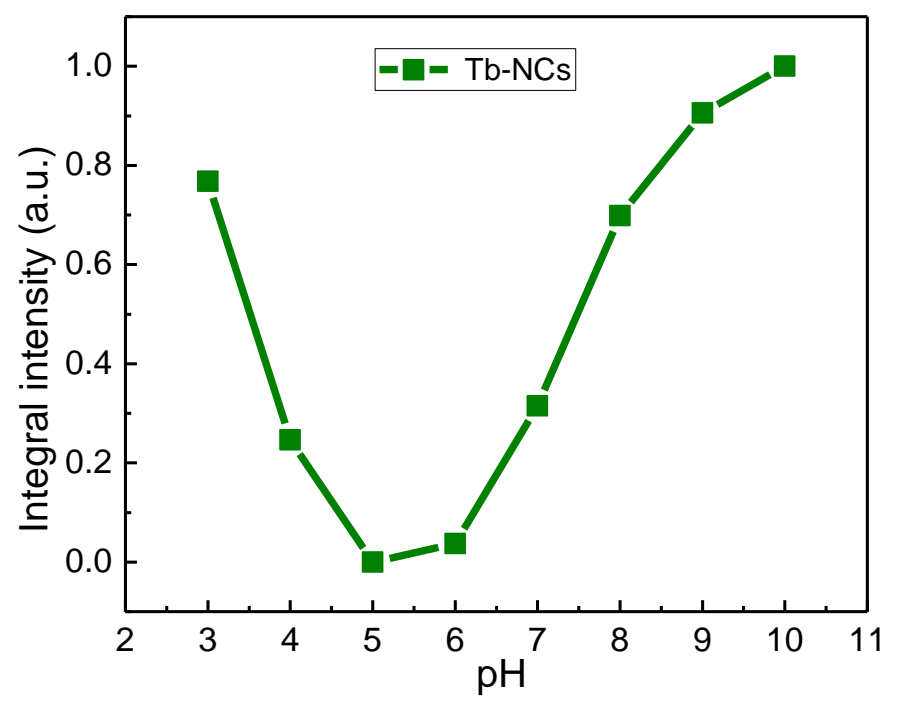

Figure S7. Integrated PL intensity of $\mathrm{Ce}^{3+}$ in $\mathrm{Tb}-\mathrm{NCs}$ at various $\mathrm{pH}$.

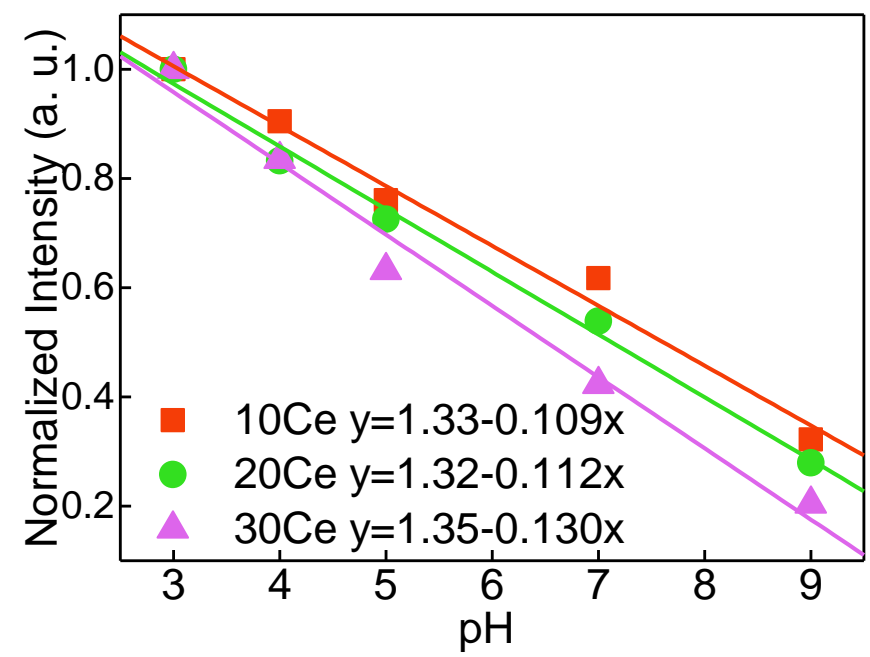

Figure S8. Integrated PL intensity profiles of $\mathrm{Tb}^{3+}$ at various $\mathrm{pH}$ with different $\mathrm{Ce}^{3+}$ doping concentration.

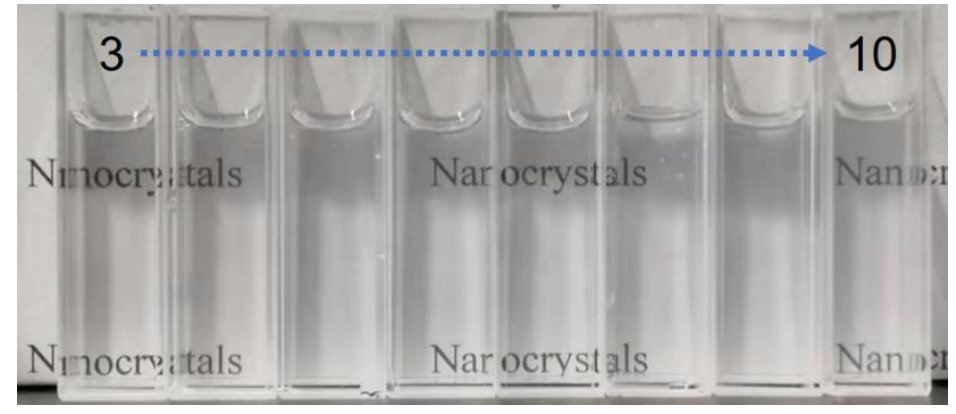

Figure S9. Photograph of Eu-NCs with different $\mathrm{pH}$ conditions under daylight. 

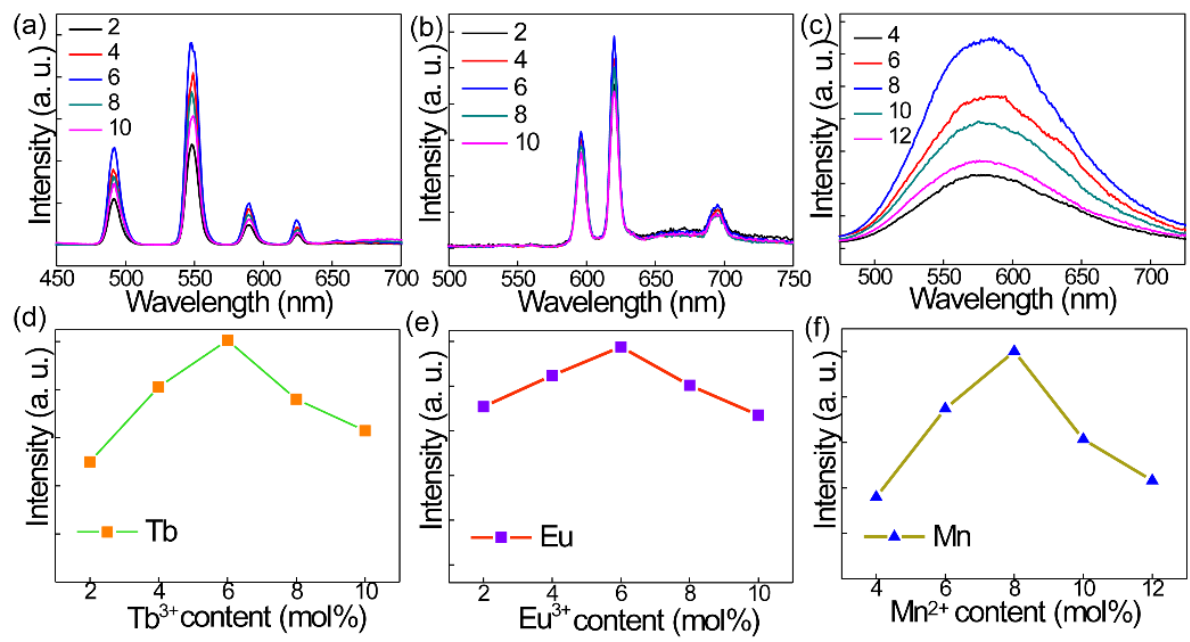

Figure S10. PL spectra of $20 \mathrm{Ce} / \mathrm{xTb}: \mathrm{NaGdF}_{4}(\mathrm{x}=2,4,6,8,10) \mathrm{NCs}(\mathrm{a}), 20 \mathrm{Ce} / \mathrm{yEu}$ :

$\mathrm{NaGdF}_{4}(\mathrm{y}=2,4,6,8,10) \mathrm{NCs}(\mathrm{b})$ and $20 \mathrm{Ce} / \mathrm{zMn}: \mathrm{NaGdF}_{4}(\mathrm{z}=4,6,8,10,12) \mathrm{NCs}(\mathrm{c})$, respectively. (d)-(f) are their corresponding integrated PL intensity profiles at various doping contents of activators.

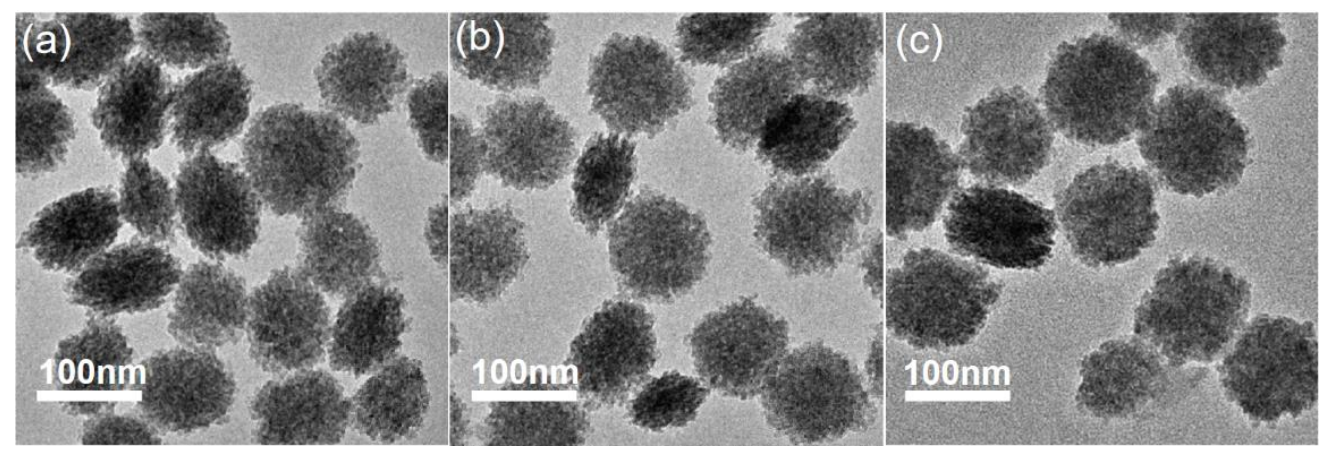

Figure S11. TEM images of $20 \mathrm{Ce} / 6 \mathrm{~Tb}$ : $\mathrm{NaGdF}_{4} \mathrm{NCs}$ dissolved in water solution at (a) $\mathrm{pH}=3$, (b) $\mathrm{pH}=7$ and (c) $\mathrm{pH}=10$.

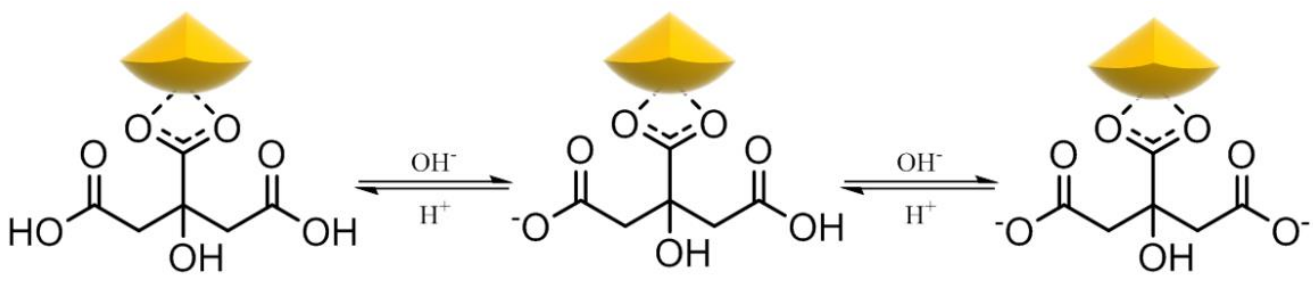

Figure S12. Schematic illustration of deprotonation process in CA under different $\mathrm{pH}$ condition. 
The $\mathrm{pH}$-dependent deprotonation in CA on the surface of NCs was investigated via Zeta potential and FTIR analysis. Firstly, the FTIR spectra reveal the existence of CA on the surface of the NCs (Figure 1c). Secondly, with the increase of $\mathrm{pH}$ from 4 to 10 , the asymmetric vibration frequency of $-\mathrm{COO}^{-}$decreases from 1598 to $1572 \mathrm{~cm}^{-1}$ and its corresponding intensity decreases as well, which reveal the transformation from $-\mathrm{COOH}$ to $-\mathrm{COO}^{-}$(Figure 3a). According to Hooke's law, $\sigma$, the vibration frequency is given as

$$
\begin{aligned}
\sigma & =\frac{1}{2 \pi c} \sqrt{\frac{K}{M}} \\
\mathrm{M} & =\frac{m_{1} m_{2}}{m_{1}+m_{2}}
\end{aligned}
$$

where $\mathrm{K}$ is the constant of chemical bond force, $\mathrm{c}$ is the velocity of light, $\mathrm{M}$ is the reduced mass. Supposing the $M$ is unchanged, a decrease of $\sigma$ suggests the reduction of $\mathrm{K}$, which is consistent with the result of ligand transformation from $-\mathrm{COOH}$ to $-\mathrm{COO}^{-}$. Thirdly, with increasing the $\mathrm{pH}$ value from 3 to 10 , the Zeta potentials decrease from +26 to $-44 \mathrm{mV}$ (Figure $3 \mathrm{~b}$ ). This analysis well supports the above statements. In a highly acidic condition, the protonated $\mathrm{CA}$ to form $-\mathrm{COOH}$ resulted in the positively charged surface, while, in a highly alkaline condition, the deprotonated $\mathrm{CA}$ to form $-\mathrm{COO}^{-}$ resulted in the negatively charged surface. 
(a)

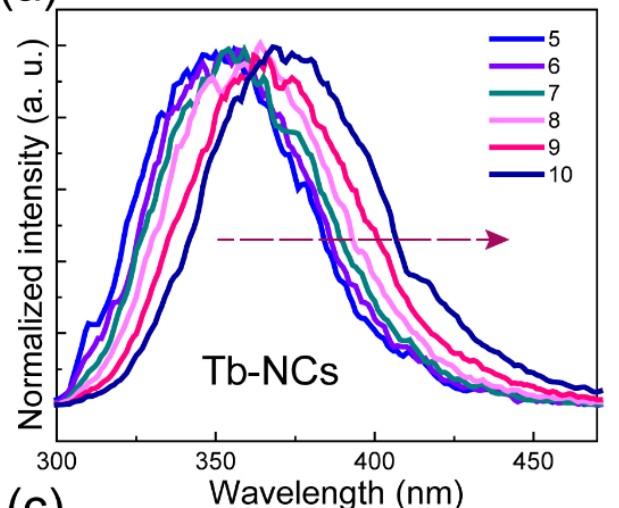

(c)

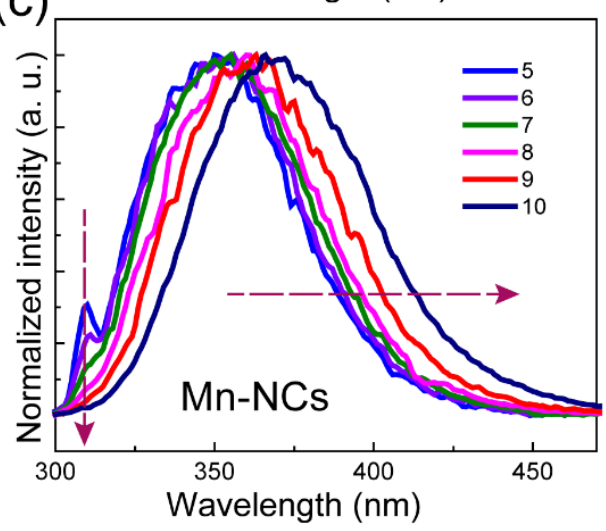

(b)

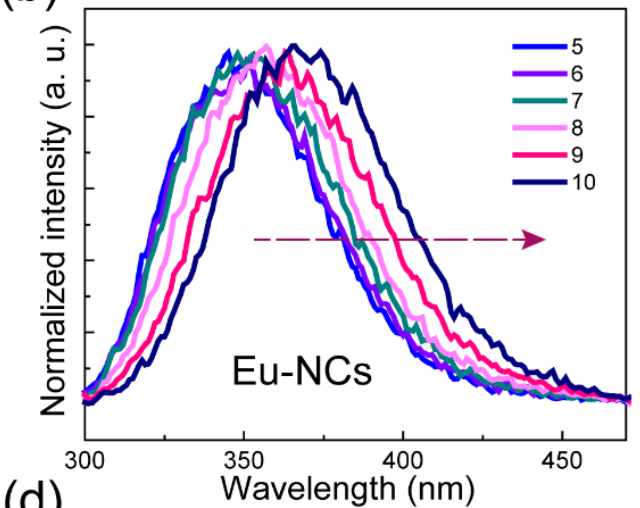

(d)

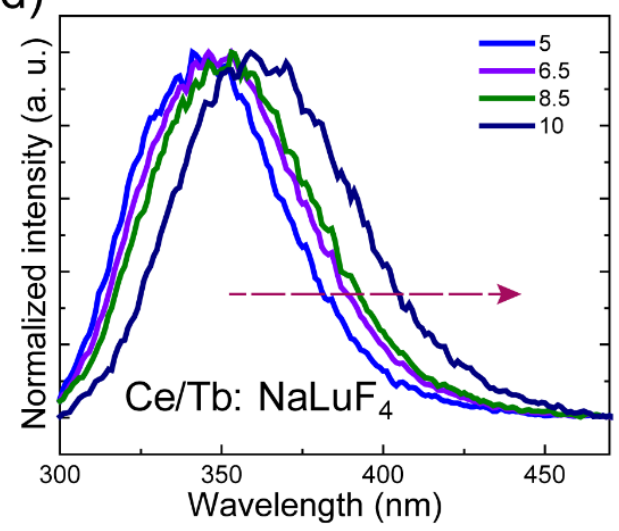

Figure S13. Normalized $\mathrm{Ce}^{3+} \mathrm{PL}$ of $\mathrm{NCs}$ at various $\mathrm{pH}$ under the excitation of 254 nm: (a) Tb-NCs, (b) Eu-NCs, (c) Mn-NCs and (d) 20Ce/6Tb: NaLuF4 NCs.
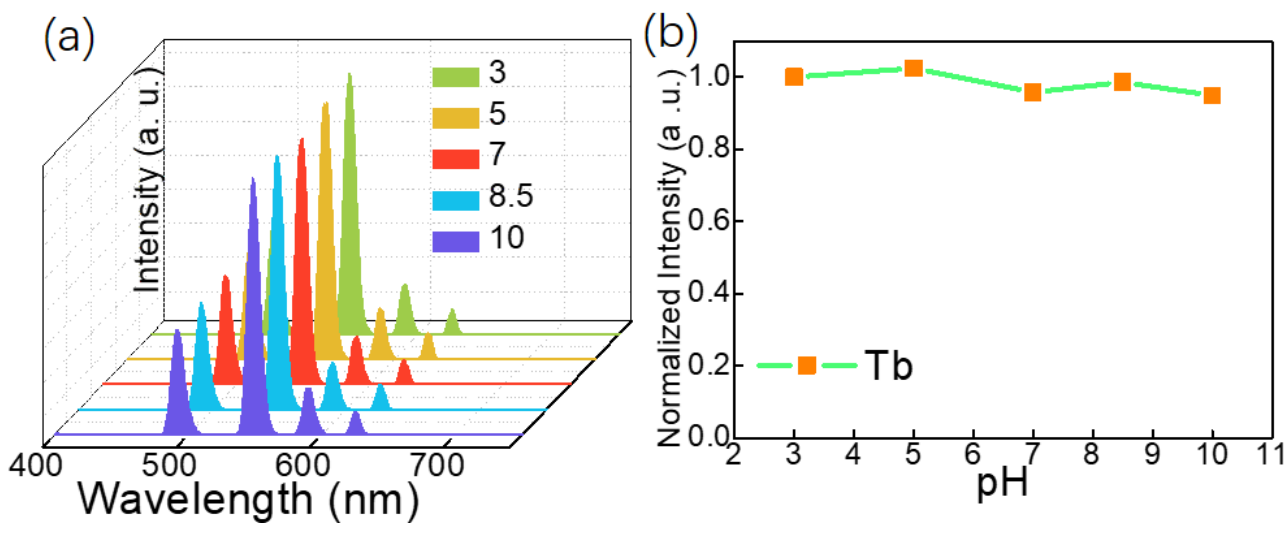

Figure S14. (a) PL spectra of $6 \mathrm{~Tb}: \mathrm{NaGdF}_{4} \mathrm{NCs}$ (without $\mathrm{Ce}^{3+}$ ) at various $\mathrm{pH}$ under the direct excitation of $\mathrm{Gd}^{3+}(272 \mathrm{~nm})$. (b) Integrated PL intensity profile at various $\mathrm{pH}$ corresponding to (a). 

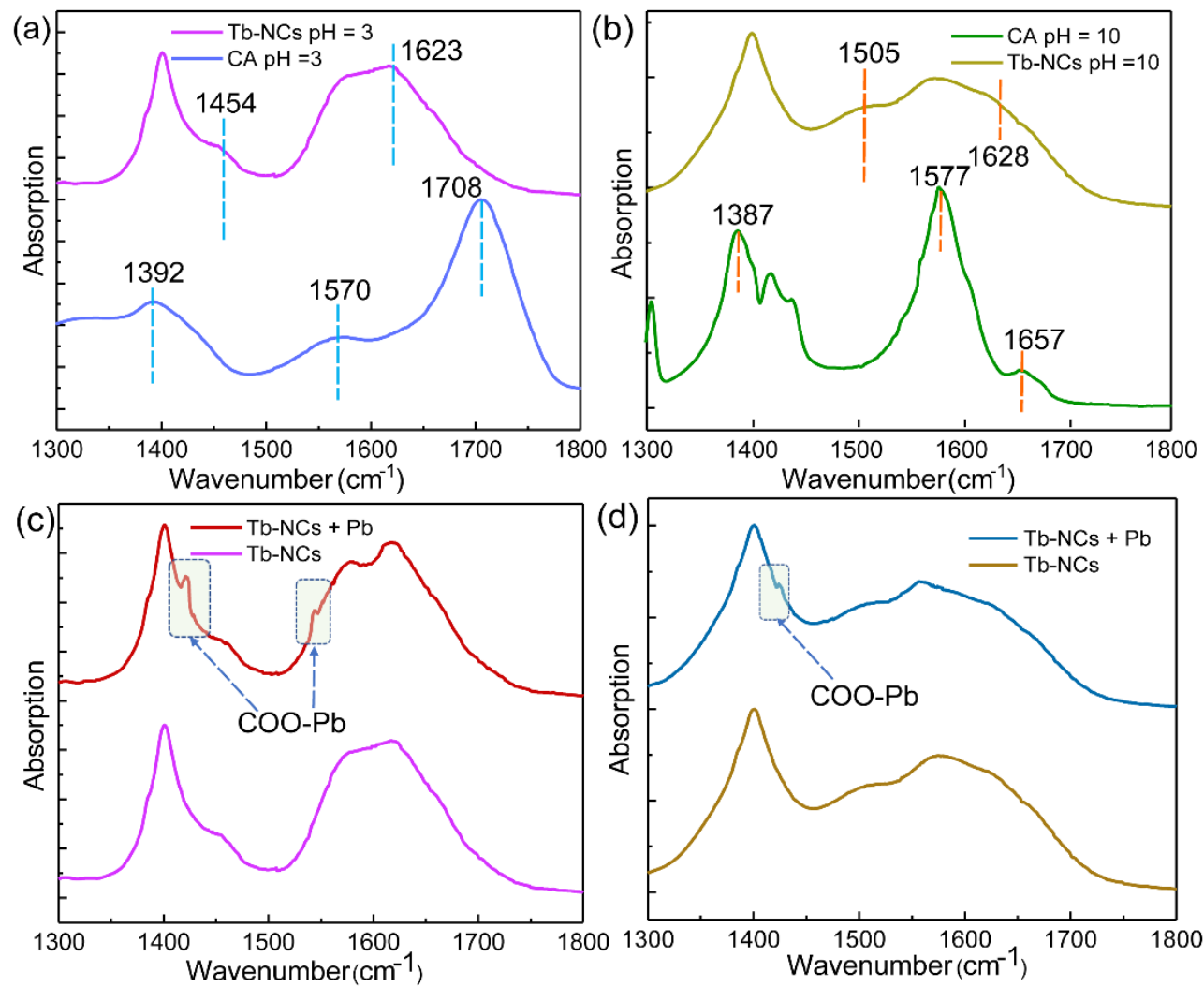

Figure S15. FTIR absorption spectra of Tb-NCs and pure CA at different $\mathrm{pH}$ : (a) $\mathrm{pH}=$

3, (b) $\mathrm{pH}=10$. FTIR absorption spectra of Tb-NCs with the addition of $\mathrm{Pb}^{2+}$ ions at (c)

$\mathrm{pH}=3$ and (d) $\mathrm{pH}=10$.

It has been widely reported that, in a presence of metal ions with carboxylic acids, new bands in the FTIR spectra could be emerged owing to new vibrational energy resulting from coordinative interaction between carboxylate group and metal ions ${ }^{\text {[S1- }}$ ${ }^{\text {S3] }}$. In this regard, the FTIR spectra of citric acid (CA) with and without Tb-NCs under different $\mathrm{pH}$ conditions were measured. As shown in Figure S15a-b, for the solution of pure $\mathrm{CA}$, the strong carbonyl $(\mathrm{C}=\mathrm{O})$ stretching band at $1708 \mathrm{~cm}^{-1}$ at $\mathrm{pH}=3$ was significantly diminished and slightly shifted to $1657 \mathrm{~cm}^{-1}$ by full deprotonation at $\mathrm{pH}=10$, while the deprotonation pronounced symmetric and asymmetric stretching bands of $\mathrm{COO}^{-}$at 1392 and $1570 \mathrm{~cm}^{-1}$, respectively, at $\mathrm{pH}=10$. These results are well 
accorded with a previous report ${ }^{[\mathrm{S} 4]}$. Contrary to the spectra of pure CA, for the Tb-NCs suspensions, the bands from $\mathrm{COO}^{-}$group at 1392 and $1570 \mathrm{~cm}^{-1}$ are observed with diminished $\mathrm{C}=\mathrm{O}$ stretching at both of $\mathrm{pH}$ conditions, which is attributable to an interaction with the surface of the nanocrystal. Notably, new broad bands appeared at 1454 and $1623 \mathrm{~cm}^{-1}$ at $\mathrm{pH}=3$, and 1505 and $1628 \mathrm{~cm}^{-1}$ at $\mathrm{pH}=10$. These results are similar to a previous report for theoretical studies on vibrational spectra in CA complexs ${ }^{[\mathrm{S} 2]}$. With forming a complex between $\mathrm{CA}$ and $\mathrm{Li}^{+}$, new bands appeared at 1275 and $1684 \mathrm{~cm}^{-1}$, corresponding to the symmetric and asymmetric stretching of the $\mathrm{COO}^{-}$group in the complex, respectively. When the CA acts as a bidentate ligand in the $\mathrm{CA} / 2 \mathrm{Li}$ complex, the symmetric and asymmetric stretching bands shift to 1375 and $1631 \mathrm{~cm}^{-1}$, respectively. The difference between the asymmetrical and symmetrical stretching of the $\mathrm{COO}^{-}$group for the $\mathrm{CA} / \mathrm{Li}$ and $\mathrm{CA} / 2 \mathrm{Li}$ is in agreement with the criteria presented by Kakihana et al. ${ }^{[\mathrm{S} 5]}$ Hence, the emergence of the new vibrational band and their shifts are attributable to the transformation of monodentate to tridentate chelation of $\mathrm{CA}$ to the $\mathrm{Tb}-\mathrm{NCs}$ at the different $\mathrm{pH}$ conditions.

Meanwhile, it has been reported that free $\mathrm{COOH}$ of citric acid could be coordinated with $\mathrm{Pb}^{2+}$ ions ${ }^{[\mathrm{S} 1, \mathrm{~S} 3]}$. As shown in Figure $\mathrm{S} 15 \mathrm{c}$, when we added $\mathrm{Pb}^{2+}$ ions $\left(\mathrm{Pb}\left(\mathrm{ClO}_{4}\right)_{2}\right)$ into the $\mathrm{Tb}-\mathrm{NCs}$ suspension and stirred for 36 hours at $\mathrm{pH}=3$, new vibration bands appeared at 1421 and $1544 \mathrm{~cm}^{-1}$, which are well accorded with the bands of bidentate complex between $\mathrm{CA}$ and $\mathrm{Pb}^{2+}$ on the surface of gold nanoparticle in a previous report ${ }^{[\mathrm{S1}]}$. But, at $\mathrm{pH}=10$, the vibrational bands for the COO-Pb complex almost disappeared (Figure S15d), which is manifesting the tridentate chelation of CA 
to the Tb-NCs and inhibiting the chelation of $\mathrm{CA}$ to the $\mathrm{Pb}^{2+}$ ions at this $\mathrm{pH}$.

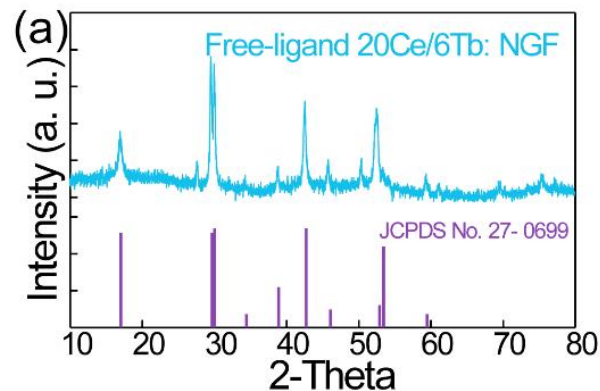

(b)
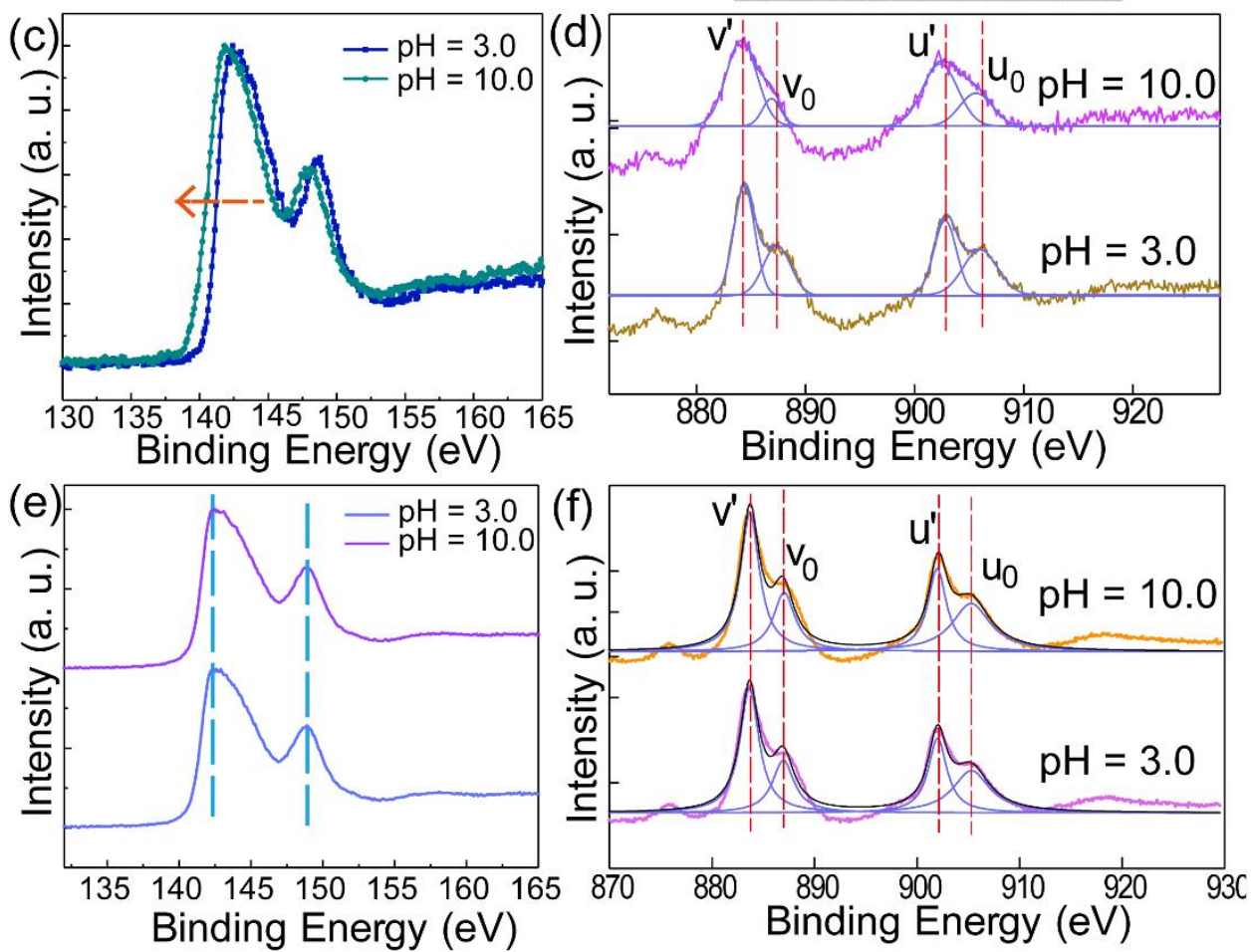

Figure S16. (a) XRD and (b) TEM image of the pure $\mathrm{NaGdF}_{4}$ : $20 \mathrm{Ce} / 6 \mathrm{~Tb} \mathrm{NCs}$ without the addition of CA in the initial reaction solution (denoted as Tb-NCs-free). Highresolution XPS spectra of the (c) Gd 4d and (d) Ce 3d under different $\mathrm{pH}$ for the TbNCs. High-resolution XPS spectra of the (e) Gd 4d and (f) Ce 3d under different pH for the Tb-NCs-free.

High-resolution X-ray photoelectron spectroscopy (XPS) spectra revealed that the binding energy of the Gd $4 \mathrm{~d}$ and $\mathrm{Ce} 3 \mathrm{~d}$ of the Tb-NCs decreased with the increasing of $\mathrm{pH}$ from 3 to 10 (Figure $\mathrm{S} 16 \mathrm{c}$ and d), while they kept unchanged for the $\mathrm{NaGdF}_{4}$ : 
20Ce/6Tb NCs without CA (denoted as Tb-NCs-free, Figure S16a, b, e, f). The results imply the degree of coordinative interaction between $\mathrm{Gd}^{3+} / \mathrm{Ce}^{3+}$ ions and $\mathrm{CA}$ at various $\mathrm{pH}$ can affect to the binding energy of inner shell electrons in the ions. Furthermore, the ratios of two pairs of binding energy peaks $\left(v^{\prime} / v_{0}\right.$ and $\left.u^{\prime} / u_{0}\right)$, corresponding to the pairs of spin-orbit doublets, in the Ce $3 \mathrm{~d}$ high-resolution XPS spectra of the Tb-NCs (Figure $\mathrm{S} 16 \mathrm{~d})^{[\mathrm{S} 6-\mathrm{S} 9]}$ increased with increase of $\mathrm{pH}$, while they almost remained the same for Tb-NCs-free (Figure S16f). All of the XPS results are providing further evidence for $\mathrm{pH}$ dependency on the coordinative interaction between lanthanide ion and CA.

Cerium is the second element in the lanthanide series, and frequently shows the +3 oxidation state, which is owing to its $4 \mathrm{f}^{1} 5 \mathrm{~d}^{1} 6 \mathrm{~s}^{2}$ electronic configuration where the three electrons in the $6 \mathrm{~s}$ and $5 \mathrm{~d}$ shells contribute to the valence. When the $4 \mathrm{f}^{1}$ electron is liberated, an exceptional +4 oxidation state will be achieved ${ }^{[\mathrm{S} 10]}$. For the trivalent cerium ions in $\mathrm{Ce}_{2} \mathrm{O}_{3}$, four peaks including two traditional photoelectron peaks $(886 \mathrm{eV}$ and $904.6 \mathrm{eV})$ and two peaks $(881.6 \mathrm{eV}$ and $900 \mathrm{eV})$ attributed to final state effects could be observed in the Ce: $3 \mathrm{~d}$ high-resolution XPS spectra. However, for the tetravalent cerium ions in $\mathrm{CeO}_{2}$, six peaks with a distinct fingerprint at $\sim 916.5 \mathrm{eV}$ could be observed in the $3 \mathrm{~d}$ high-resolution XPS spectra ${ }^{[\mathrm{S} 8, \mathrm{~S} 11-\mathrm{S} 15]}$. As shown in Figure S16d, the high-resolution XPS spectra of $\mathrm{Ce} 3 \mathrm{~d}$ in $\mathrm{Ce}\left(\mathrm{NO}_{3}\right)_{3} \cdot 6 \mathrm{H}_{2} \mathrm{O}$ at various $\mathrm{pH}$ conditions $(\mathrm{pH}=3,10)$ showed 4 typical $\mathrm{Ce}^{3+}$ peaks at almost the same positions without a pronounced peak at $\sim 916.5 \mathrm{eV}$, which indicates the trivalent oxidation state of $\mathrm{Ce}$ ion is irrelevant to the surrounding $\mathrm{pH}$ condition in $\mathrm{pH}=3 \sim 10$. 

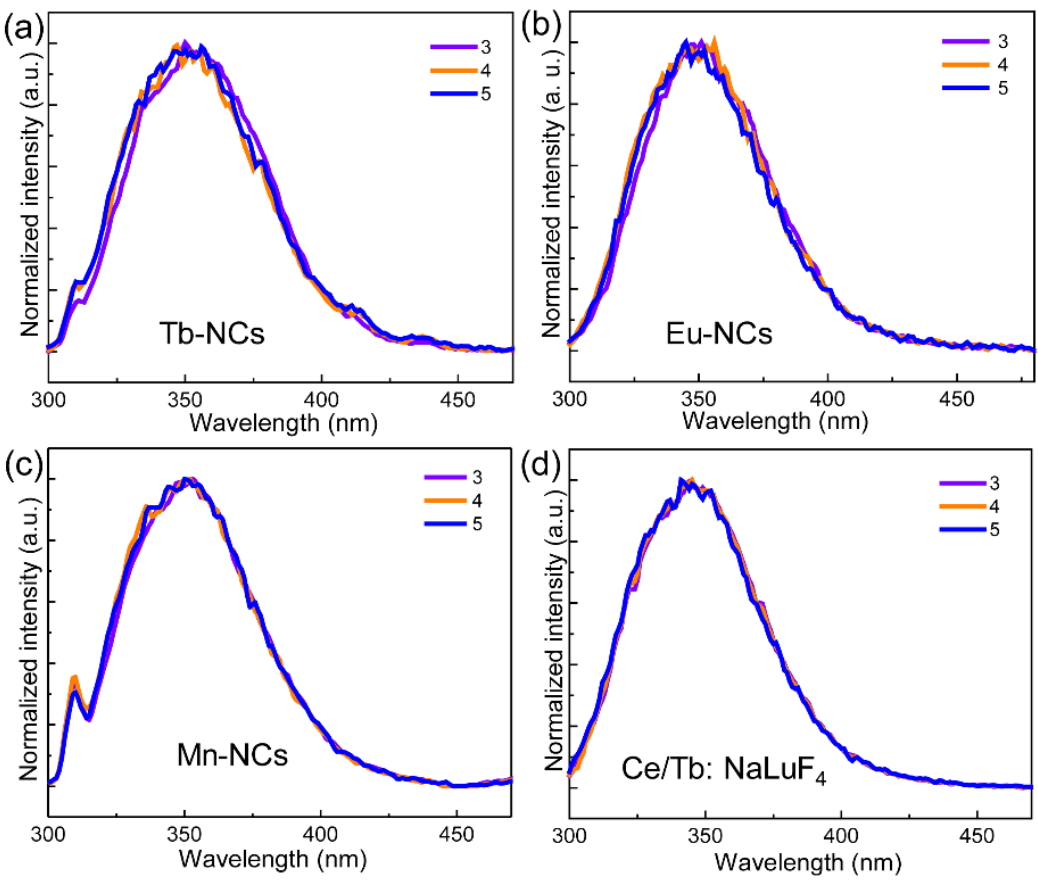

Figure S17. Normalized PL spectra of NCs at various $\mathrm{pH}$ under the excitation of 254 nm: (a) Tb-NCs, (b) Eu-NCs, (c) Mn-NCs and (d) 20Ce/6Tb: $\mathrm{NaLuF}_{4} \mathrm{NCs}$.

(a)

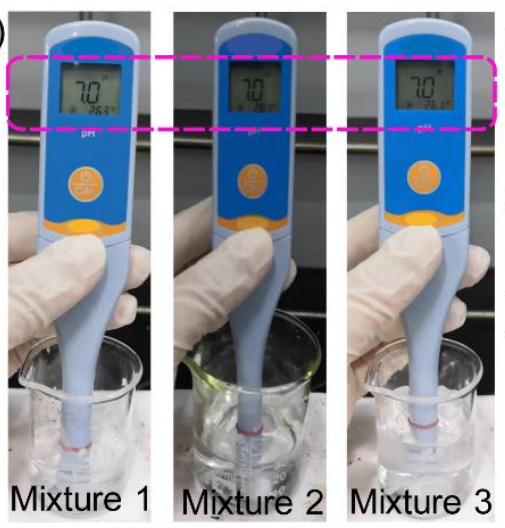

(b) 1

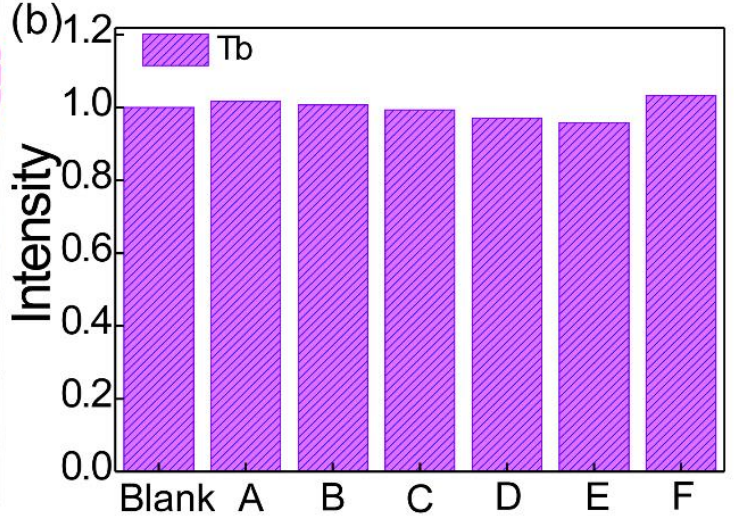

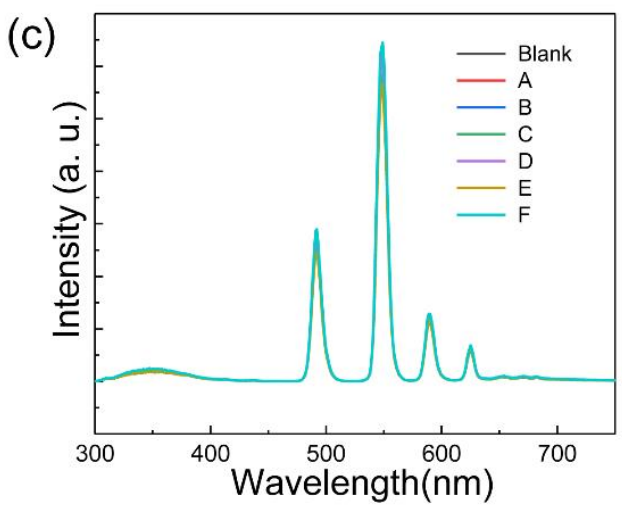

Figure S18. (a) Photographs of the as-prepared mixture 1, 2 and 3. (b) Integrated PL intensities of $\mathrm{Tb}^{3+}$ ions (b) and PL spectra of the $\mathrm{Tb}$-NCs suspension (c) in various 
impurities contained aqueous solution with $\mathrm{pH}=7$. A, $\mathrm{B}$, and $\mathrm{C}$ were the mixture 1,2 and 3, respectively. $\mathrm{D}$ represents a mixture of $\mathrm{LiCl}, \mathrm{NaCl}$, and $\mathrm{KCl}, \mathrm{E}$ represents a mixture of $\mathrm{NaCl}, \mathrm{MgCl}_{2}$, and $\mathrm{SrCl}_{2}, \mathrm{~F}$ represents a mixture of $\mathrm{KCl}, \mathrm{ZnCl}_{2}, \mathrm{CaCl}_{2}$, and $\mathrm{SrCl}_{2}$. For $\mathrm{D} \sim \mathrm{F}$, the concentration of metal chloride was $1 \mathrm{mM}$.

To reveal the effectiveness of the present studied nanocrystals for $\mathrm{pH}$ sensing at various ionic concentration and with various impurities instead of pure water, the PL intensity of the $\mathrm{Tb}-\mathrm{NCs}$ suspension in water with different concentrations of $\mathrm{HCl} / \mathrm{NaOH}$ at the same $\mathrm{pH}$ as well as with various metal salts was measured. To prepare the $\mathrm{HCl} / \mathrm{NaOH}$ mixtures with different concentrations, $100 \mu \mathrm{L} \mathrm{HCl}$ solution was added into $10 \mathrm{~mL}(100 \mathrm{mM} \mathrm{HCl}), 20 \mathrm{~mL}(50 \mathrm{mM} \mathrm{HCl})$ and $30 \mathrm{~mL}(33 \mathrm{mM} \mathrm{HCl})$ of water separately, and then the solutions were titrated with aqueous $\mathrm{NaOH}$ solution $(250 \mathrm{mM})$ to adjust $\mathrm{pH}=7$. The neutralized solutions were denoted as mixture $1(100 \mathrm{mM})$, mixture $2(50 \mathrm{mM})$ and mixture $3(33 \mathrm{mM})$, respectively (Figure S18a). As shown in Figure S18b-c, in the various ionic concentrations, the difference in PL intensities of the $\mathrm{Tb}^{3+}$ ions was irrelevant to the concentrations, indicating the $\mathrm{pH}$ sensing capability of $\mathrm{Tb}-$ NCs is reliable without any influence of the ionic strength. Since the pKa values of CA, which is key factor for our $\mathrm{pH}$ sensing system, is a constant, independently of the ionic concentrations, the concentration cannot affect to the sensing capability of our $\mathrm{pH}$ sensors. Additionally, with different concentration of metal chloride ions (see Figure 5c for $3.3 \mathrm{mM}$ and Figure S18b-c (D, E, F) for $1 \mathrm{mM})$, the PL signals were not disturbed by the interference of external metal ions again. 

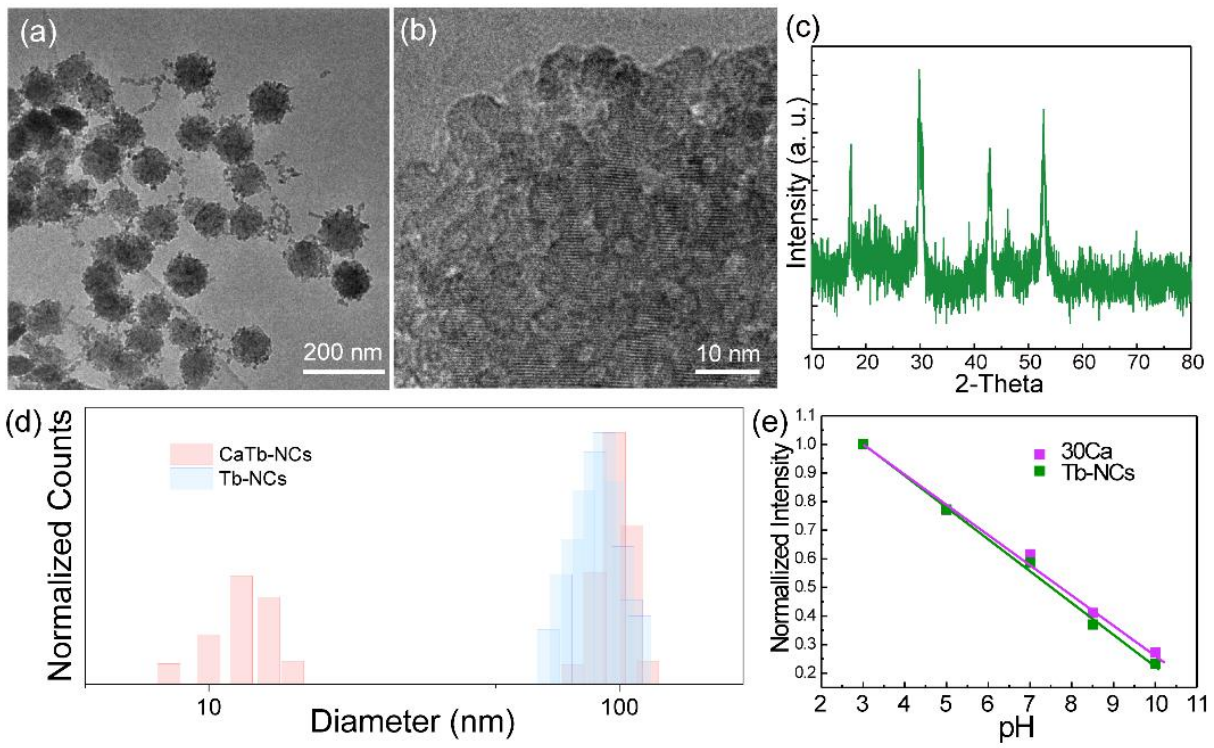

Figure S19. TEM (a), HRTEM image (b) and XRD pattern (c) of the $30 \mathrm{~mol} \% \mathrm{Ca}^{2+}$ doped Tb-NCs (CaTb-NCs). (d) Size distributions of the CaTb-NCs and Tb-NCs. (e) Normalized PL intensities of $\mathrm{Tb}^{3+}$ activators versus $\mathrm{pH}$ for the $\mathrm{CaTb}-\mathrm{NCs}$ and $\mathrm{Tb}-\mathrm{NCs}$.

As shown in Figure S19a-d, the size distribution of the CaTb-NCs, which were prepared by co-doping of $30 \mathrm{~mol} \% \mathrm{Ca}^{2+}$ ions into the $\mathrm{Tb}-\mathrm{NCs}$, was different from that of Tb-NCs. The pH sensing signal of CaTb-NCs was just slightly different from that of Tb-NCs (Figure S19e), indicating the different size distribution was not crucial to the sensing capability in this case. This result is attributable to the similar size of small NCs composing bigger NCs aggregates of Tb-NCs and CaTb-NCs (see Figure $1 \mathrm{~b}$ and Figure $\mathrm{S} 19 b$ ). It means the surface areas for both NCs, which is critical to the amount of CA accessing to $\mathrm{Ce}$ ions on the surface of the $\mathrm{NCs}$, are similar. Considering the critical role of $\mathrm{CA}$ on the $\mathrm{pH}$ sensing mechanism, the surface area is a key factor to the sensing signal intensity. However, on the other hand, the ratiometric sensing feature of our $\mathrm{pH}$ sensing NCs can also provide a reliable signal, even with a different surface area.

\section{References:}


S1. Park, J. W.; Shumaker-Parry, J. S. Structural Study of Citrate Layers on Gold Nanoparticles: Role of Intermolecular Interactions in Stabilizing Nanoparticles. J. Am. Chem. Soc. 2014, 136, 1907-1921.

S2. Ferreira, R. M.; Motta, M.; Batagin-Neto, A. Theoretical Investigation of Geometric Configurations and Vibrational Spectra in Citric Acid Complexes. Materials Research, 2014, 17, 550-556.

S3. Du, X. Z.; Liang, Y. Q. Detection of NH Stretching Signals from the Monolayers of Amino Acid Amphiphiles at the Air-Water Interface and Change of Hydrogen Bond Depending on Metal Ion in the Subphase: Infrared Reflection-Adsorption Spectroscopy. J. Phys. Chem. B. 2004, 108, 5666-5670.

S4. Mudunkotuwa, I. A.; Grassian, V. H. Citric Acid Adsorption on $\mathrm{TiO}_{2} \mathrm{Nanoparticles}$ in Aqueous Suspensions at Acidic and Circumneutral pH: Surface Coverage, Surface Speciation, and Its Impact on Nanoparticle-Nanoparticle Interactions. J. Am. Chem. Soc., 2010, 132, 14986-14994.

S5. Kakihana, M.; Nagumo, T. Coordination Structures for Uranyl Carboxylate Complexes in Aqueous Solution Studied by IR and 13C NMR Spectra. J. Phys. Chem., 1987, 91, 6128-6136.

S6. Park, K. H.; Oh, S. J. Electron-spectroscopy Study of Rare-earth Trihalides. Physical Review B, 1993, 48, 14833-14842.

S7. Barreca, D. Cerium (III) Fluoride Thin Films by XPS, Surface Science Spectra, 2006, 13, 87-93.

S8. Bêche, E.; Charvin, P.; Perarnau, D.; Abanades, S.; Flamant, G. Ce 3d XPS Investigation of Cerium Oxides and Mixed Cerium Oxide $\left(\mathrm{Ce}_{\mathrm{x}} \mathrm{Ti}_{\mathrm{y}} \mathrm{O}_{\mathrm{z}}\right)$. Surf. Interface Anal. 2008, 40, 264-267.

S9. Dawkins. K.; Rudyk. B. W.; Xu, Z.; Cadien, K. The pH-dependant Attachment of Ceria Nanoparticles to Silica using Surface Analytical Techniques. Applied Surface Science, 2015, 345, 249-255.

S10. Reidy, R. F.; Swider, K. E. Determination of the Cerium Oxidation State in Cerium Vanadate. J. Am. Ceram. Soc., 1995, 78, 1121-1122.

S11. Sims, C. M.; Maier, R. A.; Johnston-Peck, A. C.; Gorham, J. M.; Hackley, V. A.; 
Nelson, B. C. Approaches for the Quantitative Analysis of Oxidation State in Cerium Oxide Nanomaterials. Nanotechnology, 2019, 30, 085703.

S12. Eloirdi, R.; Huber, F.; Seibert, A.; Konings, R.; Gouder, T. X-ray Photoelectron Spectroscopy Study of the Reduction and Oxidation of Uranium and Cerium Single Oxide Compared to (U-Ce) Mixed Oxide Films. Applied Surface Science, 2018, 457, $566-571$.

S13. Mullins, D. R.; Overbury, S. H.; Huntley, D. R. Electron spectroscopy of single crystal and polycrystalline cerium oxide surfaces. Surf. Sci., 1998, 409, 307-319.

S14. Chen, J.; Shen, S. H.; Wu, P.; Guo, L. J. Nitrogen-doped CeOx Nanoparticles Modified Graphitic Carbon Nitride for Enhanced Photocatalytic Hydrogen Production. Green Chem., 2015, 17, 509-517.

S15. Xiong, Y. H.; Chen, S. H.; Ye, F. G.; Su, L. J.; Zhang, C.; Shen, S. F.; Zhao, S. L. Synthesis of a Mixed Valence State Ce-MOF as an Oxidase Mimetic for the Colorimetric Detection of Biothiols. Chem. Commun., 2015, 51, 4635-4638. 